\title{
An experimental study of deformation mechanism and microstructure evolution during hot deformation of Ti-6Al-2Zr-1Mo-1V alloy
}

\author{
D. He ${ }^{\text {a,b }}$, J.C. Zhu ${ }^{\text {a,* }}$, Z.H. Lai ${ }^{\text {a }}$, Y. Liu ${ }^{\text {a }}$, X.W. Yang ${ }^{\text {a }}$ \\ ${ }^{a}$ National Key Laboratory for Precision Hot Processing of Metals, Harbin Institute of Technology, Harbin 150001, China \\ ${ }^{\mathrm{b}}$ State Key Laboratory of Nonlinear Mechanics, Institute of Mechanics, Chinese Academy of Sciences, Beijing 100190, China
}

\section{A R T I C L E I N F O}

\section{Article history:}

Received 11 March 2012

Accepted 26 September 2012

Available online 11 October 2012

\section{Keywords}

Deformation mechanism

Recrystallization mechanism

Microstructure globularization

Electron backscatter diffraction

Titanium alloys

\begin{abstract}
A B S T R A C T
Isothermal tensile tests have been performed to study the deformation mechanisms and microstructure evolution of Ti-6Al-2Zr-1Mo- $1 \mathrm{~V}$ titanium alloy in the temperature range $750-850{ }^{\circ} \mathrm{C}$ and strain rate range $0.001-0.1 \mathrm{~s}^{-1}$. The deformation activations have been calculated based on kinetics rate equation to investigate the hot deformation mechanism. Microstructures of deformed samples have been analyzed by electron backscatter diffraction (EBSD) to evaluate the influences of hot deformation parameters on the microstructure evolution and recrystallization mechanism. The results indicate that deformation mechanisms vary with deformation conditions: at medium $\left(800^{\circ} \mathrm{C}\right)$ and high $\left(850^{\circ} \mathrm{C}\right)$ temperature, the deformation is mainly controlled by the mechanisms of dislocation creep and self-diffusion, respectively. The microstructure globularization mechanisms also depend on deformation temperature: in the temperature range from 750 to $800^{\circ} \mathrm{C}$, the high angle grain boundaries are mainly formed via dislocation accumulation or subgrain boundaries sliding and subgrains rotation; while at high temperature of $850^{\circ} \mathrm{C}$, recrystallization is the dominant mechanism. Especially, the evolution of the recrystallization mechanism with the deformation temperature is first observed and investigated in TA15 titanium alloy. (C) 2012 Elsevier Ltd. All rights reserved.
\end{abstract}

\section{Introduction}

TA15 titanium alloy with a nominal composition of Ti-6Al-2Zr$1 \mathrm{Mo}-1 \mathrm{~V}$, is developed on the basis of Russia alloy BT20 [1]. As a classic near $\alpha$ titanium alloy, TA15 is an ideal high-temperature alloy since it combines the excellent creep behavior of $\alpha$ titanium alloys with the high strength of $\alpha+\beta$ titanium alloys [2]. Therefore, TA15 is preferentially used in aerospace field in China to produce the compressor blades, compressor disks of gas turbine engine and large front fans of modern jet engines [3].

Generally, because of high yield strength and relatively low elastic modulus, the fabrication and forming operation of TA15 titanium alloy are usually conducted at elevated temperature, such as $\alpha+\beta$ forming (deformed in the temperature range $30-200{ }^{\circ} \mathrm{C}$ below the $\beta$-transus), $\beta$ deforming (deformed at a temperature above the $\beta$-transus) [4,5]. On the other hand, since TA15 alloy is close to single phase, the influence of traditional heat treatment on the microstructure is not as obvious as that for other metal alloys, e.g. steels. Therefore, thermomechanical processing is usually adopted to control both the shape size and the microstructure morphology/composition of the near $\alpha$ titanium alloy part [6].

Recent research results indicate that the hot deformation mechanisms of titanium alloys, which are generally controlled by thermal

\footnotetext{
* Corresponding author. Tel.: +86 451 86413792; fax: +86 45186413922.

E-mail address: fgms@hit.edu.cn (J.C. Zhu).
}

activation [7], are not only influenced by the alloying elements [8] and initial microstructure [9], but also depended on the deformation temperature, strain and strain rate $[10,11]$. On the other hand, the microstructure evolutions, e.g. $\alpha \leftrightarrow \beta$ phase transformation, $\alpha$ lamellae globalization, grain coarsening and recrystallization nuclei and their growth, are also complex and significantly affected by hot deformation parameters $[12,13]$. This implies that a strong interaction relationship between the microstructure evolution and hot deformation behavior/mechanism exists during hot deformation process [14]. Therefore, the study of hot deformation mechanism and microstructure evolution is very important and has attracted more and more researchers' attentions.

With regard to hot deformation behavior and mechanism, many studies have been carried out on titanium $[7,15]$ and titanium alloys $[8,11-13]$ by combining compressive or tensile deformation behavior with thermal activation energy analysis. However, up to now, only a few studies have been conducted on the hot deformation mechanism of near $\alpha$ titanium. Especially, for TA15 titanium alloy, although the microstructure evolution and mechanism properties of TA15 titanium alloy under multi-step local loading forming have been studied by Sun et al. [16], the deformation mechanisms are roughly summarized as dynamic recrystallization according to the peak and steady status phenomenon of flow stress curves or the appearance of equiaxed $\alpha$ grains. Obviously, they are not enough for us to deeply understand the hot deformation mechanisms and the microstructure evolutions. Taking the appearance 
of equiaxed $\alpha$ grains for example, many hypotheses could account for it, e.g. laths shearing and interfaces migration by diffusion [17], DDRX [18], CDRX [19], rotational dynamic recrystallization (RDRX) [20] and geometric dynamic recrystallization (GDRX) [21,22].

The objective of the current work is focused on the hot deformation mechanism and microstructure evolution of TA15 titanium alloy in the deformation temperature range of $750-850{ }^{\circ} \mathrm{C}$ and strain rate range between 0.001 and $0.1 \mathrm{~s}^{-1}$. The rest of the paper is arranged as follows. Firstly, tensile tests have been performed under different considerations; then, the deformation behaviors and mechanisms have been evaluated based on the obtained stressstrain curves and calculated deformation activations. Subsequently, microstructure evolutions have been deeply investigated by combination of electron backscatter diffraction (EBSD) technique. Finally, the deformation mechanism, $\alpha$ lamellae globalization, recrystallization mechanism and their evolutions depending on deformation conditions have been further discussed and summarized.

\section{Experimental procedure}

\subsection{Materials and sample preparation}

The chemical composition of used TA15 titanium alloy is given in Table 1 . The $\beta$-transus temperature of used TA15 alloy was $993^{\circ} \mathrm{C}$. The initial microstructure consisted of coarse primary $\alpha$ phase (hexagonal close-packed, hcp) lamellae $\left(\alpha_{\mathrm{p}}\right)$, relatively fine

Table 1

Chemical composition of used TA15 alloy (mass fraction, \%).

\begin{tabular}{llllll}
\hline $\mathrm{Al}$ & $\mathrm{Zr}$ & $\mathrm{Mo}$ & $\mathrm{V}$ & $\mathrm{Fe}$ & $\mathrm{Ti}$ \\
\hline 6.47 & 1.59 & 1.45 & 1.91 & 0.038 & Bal. \\
\hline
\end{tabular}

second $\alpha$ lamellae $\left(\alpha_{s}\right)$ and a few retained $\beta$ phase (body-centered cubic, bcc) layer $\left(\beta_{\mathrm{r}}\right)$, as shown in Fig. 1 . The average size of primary $\alpha$ lamellae is $10 \mu \mathrm{m}$ in thickness and $35-40 \mu \mathrm{m}$ in length; while for second $\alpha$ lamellae, the values are $2-2.5 \mu \mathrm{m}$ and approximately $15 \mu \mathrm{m}$, respectively.

Flat tension samples of $49 \mathrm{~mm}$ length and $2 \mathrm{~mm}$ thickness were machined along the elongated direction from the mentioned TA15 titanium alloy wrought bars, as shown in Fig. 2. It is noteworthy that the non-standard tensile specimens were used in the tensile deformation experiment. This is because that we are focused on the deformation mechanism and microstructure evolution during hot tensile deformation process but not on the standard high temperature tensile mechanical properties (e.g. tensile strength, yield stress and elongation) of this material in the current study. The tensile deformation were carried out in a high-temperature tensile testing machine (INSTRON 5500R) at three temperatures $(750,800$ and $\left.850^{\circ} \mathrm{C}\right)$ and three constant strain rates $\left(0.001,0.01,0.1 \mathrm{~s}^{-1}\right)$, respectively.

In order to take the influence of deformation strain into consideration, the tensile tests stop at different strains, i.e. 0.02 or 0.04 , $0.10,0.20$, respectively. The detailed parameters are listed in Table 2. All specimens were mounted on the holder when the furnace temperature reaching to the given temperature and then heated to test temperature again. All specimens were held for $3 \mathrm{~min}$ at test temperature to improve the temperature uniformity of whole specimen and then deformed to given strain. After tensile deformation, the specimens were quenched in cold water immediately in order to maintain the microstructure characteristics at high temperature.

\subsection{EBSD measurement and microstructure analysis}

Microstructure and local crystallographic orientations of deformed samples were examined by EBSD techniques. For this
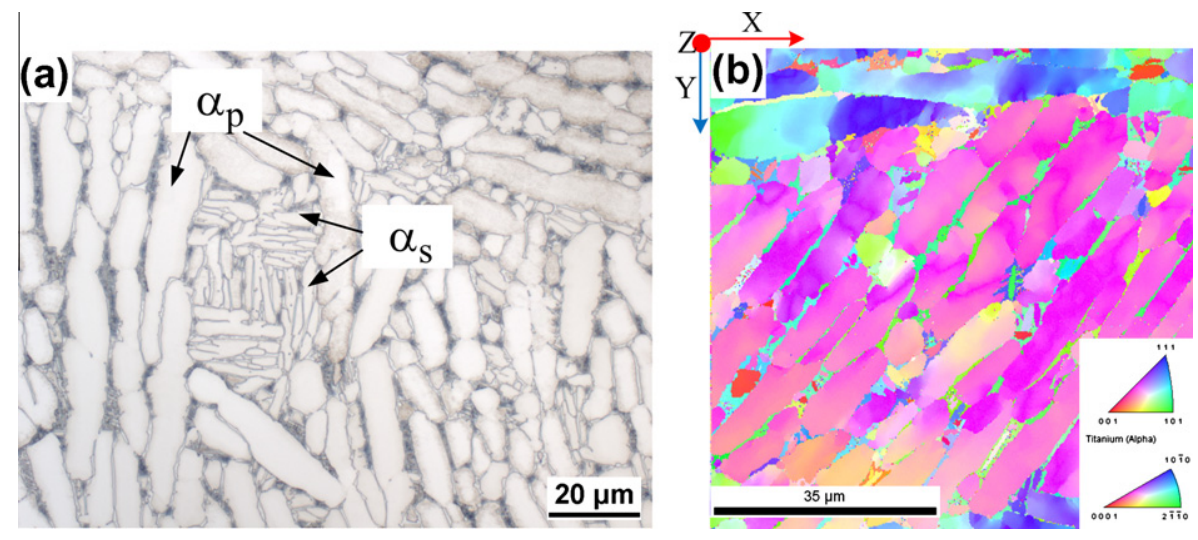

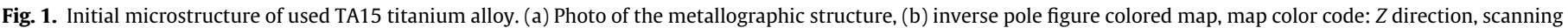
step size: of $0.2 \mu \mathrm{m}$.
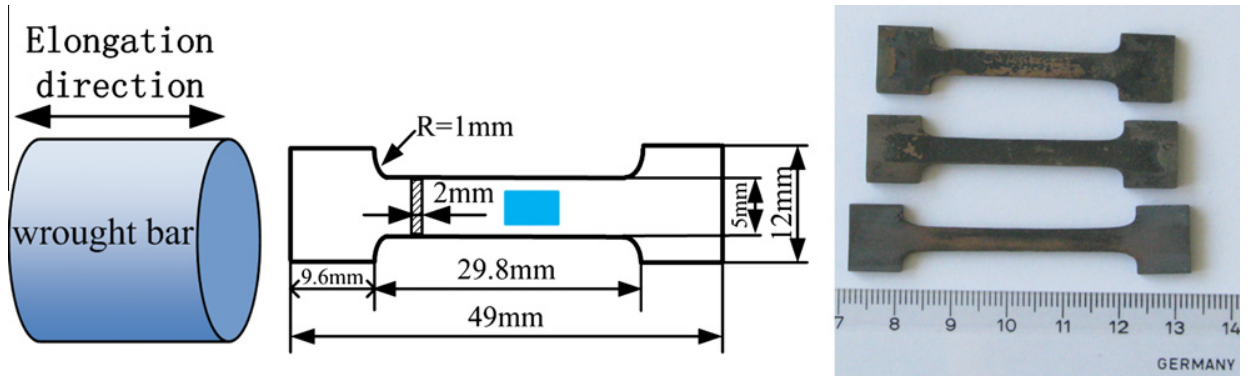

Fig. 2. The sketch map of tensile sample machining, geometry of the tensile sample and sample photo after tensile deformation. 
Table 2

Detailed parameters for tensile deformation test.

\begin{tabular}{llll}
\hline Test no. & Deformation strain & Strain rate $\left(\mathrm{s}^{-1}\right)$ & Temperature $\left({ }^{\circ} \mathrm{C}\right)$ \\
\hline $1 / 2 / 3$ & $0.02 / 0.10 / 0.19$ & 0.001 & 750 \\
$4 / 5 / 6$ & $0.04 / 0.10 / 0.19$ & 0.01 & 750 \\
$7 / 8 / 9$ & $0.04 / 0.10 / 0.19$ & 0.1 & 750 \\
$10 / 11 / 12$ & $0.02 / 0.10 / 0.19$ & 0.001 & 800 \\
$13 / 14 / 15$ & $0.04 / 0.10 / 0.19$ & 0.01 & 800 \\
$16 / 17 / 18$ & $0.02 / 0.10 / 0.19$ & 0.1 & 800 \\
$19 / 20 / 21$ & $0.02 / 0.10 / 0.19$ & 0.001 & 850 \\
$22 / 23 / 24$ & $0.04 / 0.10 / 0.19$ & 0.01 & 850 \\
$25 / 26 / 27$ & $0.04 / 0.10 / 0.19$ & 0.1 & 850 \\
\hline
\end{tabular}

purpose, the flat surfaces of tensile samples were prepared through standard grinding and polishing routines (ASTM: ASTM E3-11). The final polishing with a polishing solution consisting of colloidal silica (OP-S, 90 vol.\%) and H2O2 (10 vol.\%) was performed. Long time (30 min) for final polishing is to minimize the strain caused by the grinding and polishing processes.

EBSD measurements were carried out on a JEOL 6500F scanning electron microscope equipped with an EBSD system developed by $\mathrm{EDAX} / \mathrm{TSL}^{\circledR}$. In order to facilitate comparison, the central region of each tensile deformed specimen was selected for EBSD measurements (see the blue ${ }^{1}$ region in Fig. 2). The grain size and morphology, crystal orientations, grain or subgrain boundaries and such other microstructure characteristics were processed and analyzed by the EDAX-TSL OIM ${ }^{\mathrm{TM}} 5.4$ software.

\section{Results}

\subsection{Tensile deformation behavior}

The tensile load-displacement curves of TA15 titanium alloy achieved by isothermal tensile test under different deformation conditions are shown in Fig. 3. The results indicate that the tensile load decreases with the increase of deformation temperature and decrease of strain rate. Generally, the tensile load rapidly increases to a peak, then starts to decrease continuously, and finally attains a steady state. Such tensile deformation behavior is usually considered as a characteristic for hot working accompanied by dynamic recrystallization (DRX) $[23,24]$.

\subsection{Kinetic analysis}

As mentioned in the introduction, the high temperature deformation behavior of alloys is mainly controlled by thermal activation [8]. Commonly, the temperature and strain rate dependence of flow stress in hot deformation can be described by Arrhenius kinetic rate equation given by $[25,26]$ :

$\dot{\varepsilon}=A \sigma^{n} \exp \left(-\frac{Q}{R T}\right)$

where $\dot{\varepsilon}$ is the strain rate $\left(\mathrm{s}^{-1}\right), A$ is a material constant, $\sigma$ is the flow stress (MPa), $n$ is the stress exponent, $Q$ is the activation energy $\left(\mathrm{kJ} \mathrm{mol}^{-1}\right), R$ is the gas constant, and $T$ is the temperature in Kelvin (K).

To facilitate obtaining the kinetic parameters $n$ and $Q$ the Eq. (1) can be written as:

$\ln (\dot{\varepsilon})=\ln (A)+n \ln (\sigma)-Q /(R T)$

Thus, when $T$ is constant, one defines, from Eq. (2).

\footnotetext{
${ }^{1}$ For interpretation of color in Figs. 1, 2, 4-12 the reader is referred to the web version of this article.
}

$m=\left.\frac{\partial \ln \sigma}{\partial \ln \dot{\varepsilon}}\right|_{T}$

where $m$ represents the strain-rate sensitivity of flow stress, $m=1$ / $n$.

When $\dot{\varepsilon}$ is constant, $Q$ also can be derived from Eq. (2) and written as:

$Q=\left.R \frac{1}{m} \frac{\partial \ln \sigma}{\partial \ln (1 / T)}\right|_{\dot{\varepsilon}}$

The values of calculated $n$ and $Q$ under different deformation conditions are listed in Table 3. The results show a good agreement with research work of others under certain conditions, i.e. when the titanium or titanium alloys were deformed at low temperature (here, less than $850^{\circ} \mathrm{C}$ for TA15) and low strain rate (less than $0.1 \mathrm{~s}^{-1}$ ) [8,26-28]. It can be seen that the values of calculated $n$ are temperature-dependent (decreased from 7.28 to 3.86 ) in the temperature range $750-850^{\circ} \mathrm{C}$. Similarly, the activation energy $Q$ also decreases from 697.44 to $163.28 \mathrm{~kJ} \mathrm{~mol}^{-1}$ as the temperature increases from 750 to $850{ }^{\circ} \mathrm{C}$. The obvious variations of calculated $n$ and $Q$ further indicate that different deformation mechanisms may exist in the temperature range $750-850{ }^{\circ} \mathrm{C}$ at low strain rate.

\subsection{Grain morphology and size evolution}

Before analyzing the grain morphology and size evolution during tensile deformation, we must note that three temperatures $\left(750,800\right.$ and $850^{\circ} \mathrm{C}$ ) were used in this study. The microstructures of samples at three test temperatures but without any tensile deformation were given by Fig. 4. Obviously, the microstructure of samples at three different temperatures (i.e. 750, 800 and $850^{\circ} \mathrm{C}$ ) are similar: all of them are composed of thick primary $\alpha$ lamellae $\left(\alpha_{\mathrm{p}}\right)$, some coarse equiaxed $\alpha$ grains and a few retained $\beta$ phase. With the increasing of temperature, the thickness of $\alpha$ lamellae increases slightly: its mean value increases from $6.9 \mu \mathrm{m}$ at $750{ }^{\circ} \mathrm{C}$ to $8.1 \mu \mathrm{m}$ at $850{ }^{\circ} \mathrm{C}$. Furthermore, the volume fraction of equiaxed $\alpha$ grains also increases as the temperature increases, as shown in Fig. 4c. This is mainly resulted by the coarsening and ripening effects of some short or small $\alpha$ grains at higher temperature (i.e. $850{ }^{\circ} \mathrm{C}$ at here).

Although the microstructures at different temperatures are little different, they will not significantly affect the following recrystallization mechanism studies. This is because that we are focused on the evolutions of "newly formed" small and equiaxed $\alpha$ grains but not on the original coarse microstructure. Furthermore, when we study the influences of tensile strain or strain rate on the evolution of microstructure, the results from the samples deformed at different strains or strain rates but at same given test temperature, are compared and analyzed.

The microstructures of the TA15 titanium alloy after tensile deformation $(\varepsilon=0.19)$ at strain rate of $0.01 \mathrm{~s}^{-1}$ and in temperature range $750-850^{\circ} \mathrm{C}$ are presented as a unique color map in Fig. 5.

It is obvious that the microstructure evolution is strongly dependent on deformation temperature. At low temperature $\left(750{ }^{\circ} \mathrm{C}\right)$, although a lot of equiaxed $\alpha$ grains are observed, there are still a certain number of $\alpha$ lamellae, as seen from the top region in Fig. 5a. With increasing deformation temperature, the lamellae globalization process is smoothly developed: the fractions (in grain numbers) of equiaxed $\alpha$ grains (aspect ratio less than 2 ) increase to $67 \%$ and $85 \%$ at 800 and $850{ }^{\circ} \mathrm{C}$, respectively. Few $\alpha$ lamellae appear at the strain of 0.19 and temperature of $850^{\circ} \mathrm{C}$, as shown in Fig. 5c.

Besides of the obvious lamellae globalization, the average grain size also decreased from $9.43 \mu \mathrm{m}$ to $2.5 \mu \mathrm{m}$ (in diameter) as the temperature increased from 750 to $850^{\circ} \mathrm{C}$. This result is mainly caused by the increase in the number of "new" grains with small 

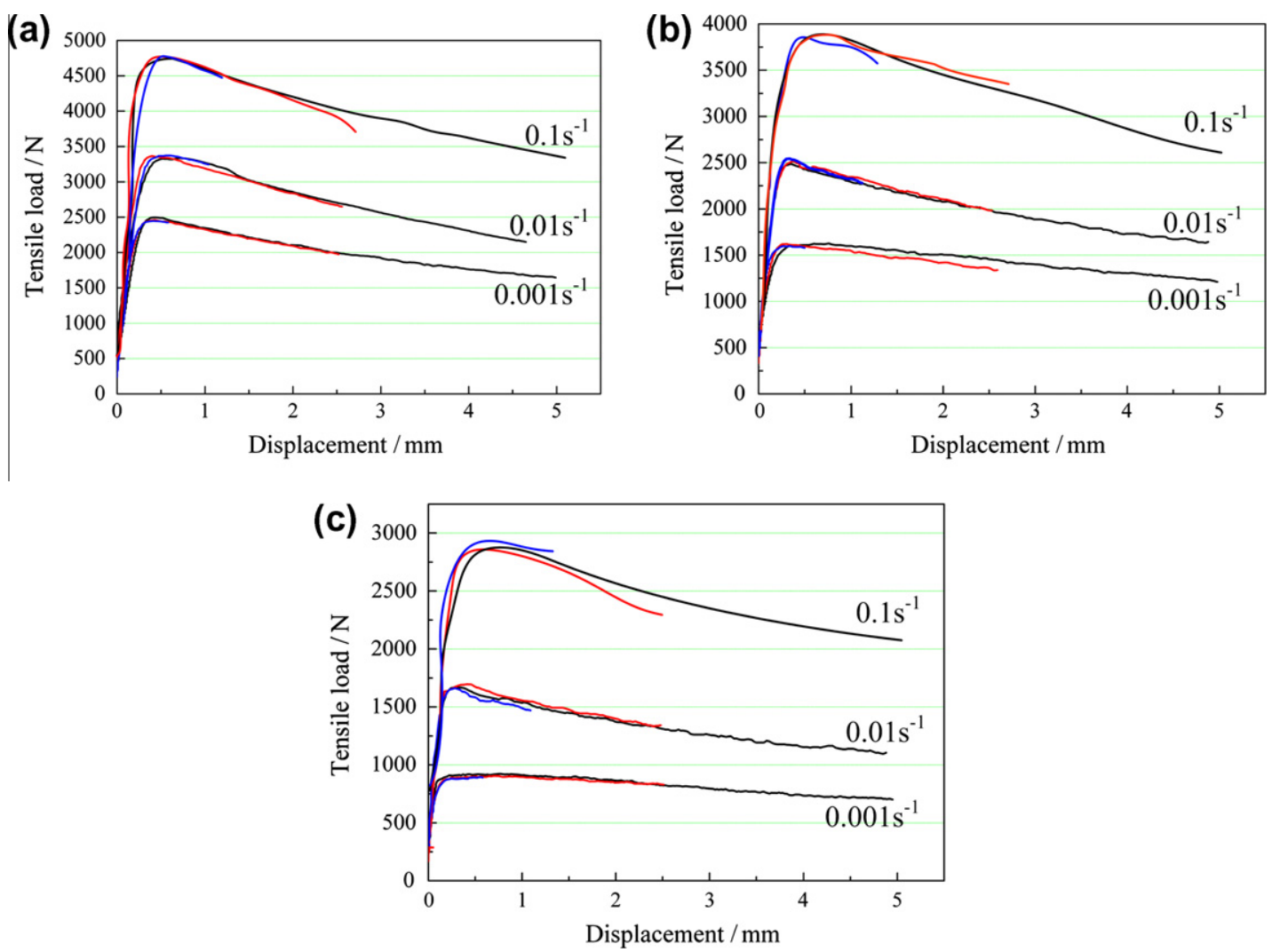

Fig. 3. Tensile load-displacement curves under various deformation conditions during hot tensile deformation. (a) $750{ }^{\circ} \mathrm{C}$, (b) $800{ }^{\circ} \mathrm{C}$, and (c) $850{ }^{\circ} \mathrm{C}$.

Table 3

Values of calculated $n$ and $Q$ under different deformation conditions.

\begin{tabular}{llll}
\hline \multicolumn{2}{l}{ Deformation conditions } & $n$ & $\mathrm{Q}\left(\mathrm{kJ} \mathrm{mol}^{-1}\right)$ \\
\cline { 2 - 3 } Strain rate $\left(\mathrm{s}^{-1}\right)$ & Temperature $\left({ }^{\circ} \mathrm{C}\right)$ & & \\
\hline $0.001-0.1$ & 750 & 7.28 & 697.44 \\
& 800 & 5.26 & 357.87 \\
& 850 & 3.86 & 163.28 \\
\hline
\end{tabular}

size. The distribution maps of grains with diameter less than $4 \mu \mathrm{m}$ are shown in Fig. 6. Obviously, the number of small "new" grains (color grains) increased with increasing deformation temperature. These small "new" grains distributed along the original grain boundaries (indicated by black line) and some of them even formed a "necklace structure", which is usually identified as one of characteristics of recrystallization $[23,29,30]$.

\subsection{Grain and subgrain boundary structure evolution}

The grain-subgrain boundary (GSB) evolutions with increasing deformation strain at different temperatures and deformation strains are shown in Figs. 7-9. In these GSB maps, the red, green and blue lines represent the low angle boundaries $\left(<5^{\circ}\right)(\mathrm{LAB})$, medium angle boundaries (between $5^{\circ}$ and $\left.15^{\circ}\right)(\mathrm{MAB})$ and high angle boundaries $\left(>15^{\circ}\right)(\mathrm{HAB})$, respectively. No twin boundaries are detected under all test conditions.
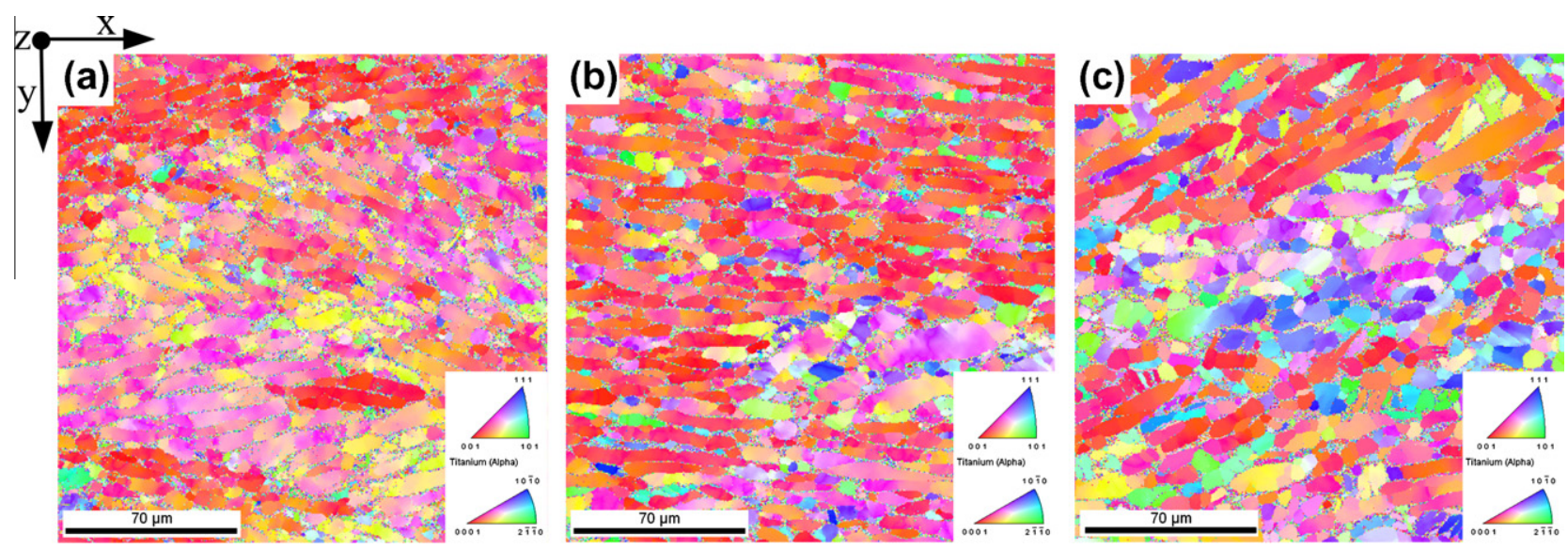

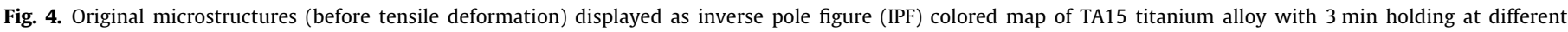
temperatures, color code: $Z$ direction; scanning step size: $0.1 \mu \mathrm{m}$. (a) $750{ }^{\circ} \mathrm{C}$, (b) $800^{\circ} \mathrm{C}$, and (c) $850^{\circ} \mathrm{C}$. 

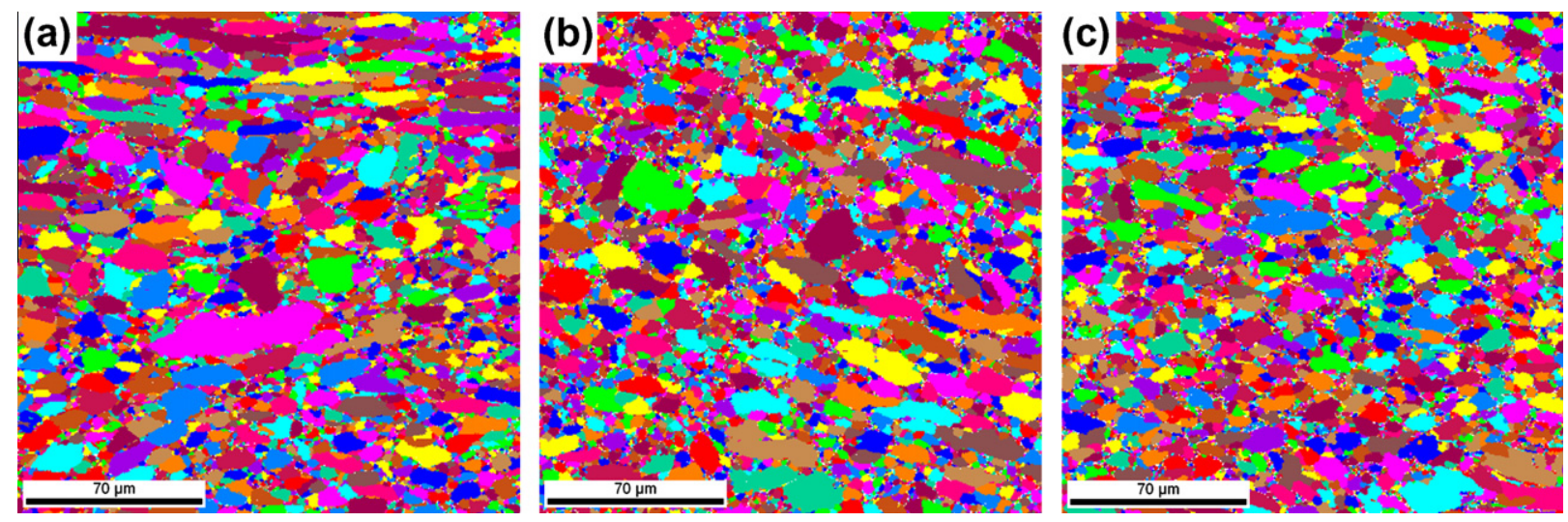

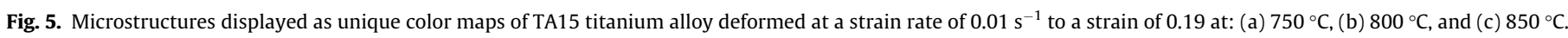
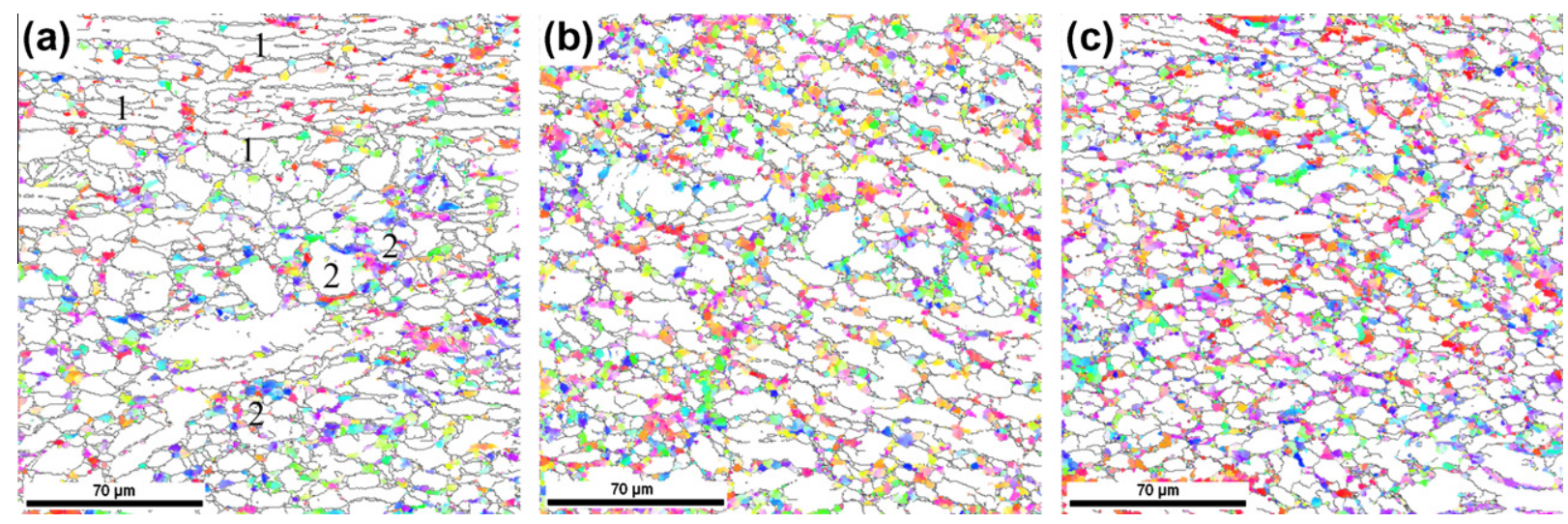

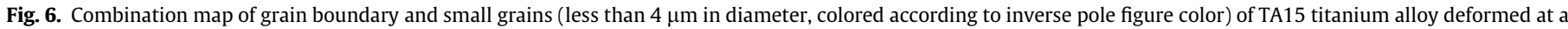
strain rate of $0.01 \mathrm{~s}^{-1}$ to a strain of 0.19 at: (a) $750{ }^{\circ} \mathrm{C}$, (b) $800{ }^{\circ} \mathrm{C}$, and (c) $850{ }^{\circ} \mathrm{C}$.

At temperature of $750{ }^{\circ} \mathrm{C}$, the total density of subgrain boundary (less than $\left.15^{\circ}\right)(\mathrm{SB})$ is relatively low and its distribution is heterogeneous at strain 0.04 , as shown in Fig. 7a. A lot of equiaxed grains containing few SBs are detected in the top region of Fig. 7a. The results analysis shows that these equiaxed grains usually have a high Schmid factor value (larger than 0.4 ) for basal slip systems. However, almost all of the lamellae in the half bottom region contain a high density of SBs. In this zone, most of grains have a low Schmid factor values (less than 0.1 ) for basal slip systems. With increasing strain, the evolution of grain and subgrain structure is very obvious. The densities of new formed HABs increase dramatically as the strains increase from 0.04 to 0.10 and 0.20 , as shown in Fig. 7(a-c), respectively. Most of the new formed HABs distribute along the original coarse grain boundaries. However, they are usually accompanied with high density of SBs, as seen from the magnification maps in Fig. 7(b and c).

When the tensile deformation temperature increased to $800^{\circ} \mathrm{C}$, some new grains containing few subgrain boundaries appear along the original coarse grain boundaries, as seen from the magnification maps in Fig. 8(b and c). With increasing tensile strain, the number of new grains increased steadily, i.e. the new grains with HABs distributes along the original grain and a "necklace structure" was formed, as seen from the magnification map in Fig. 8c.
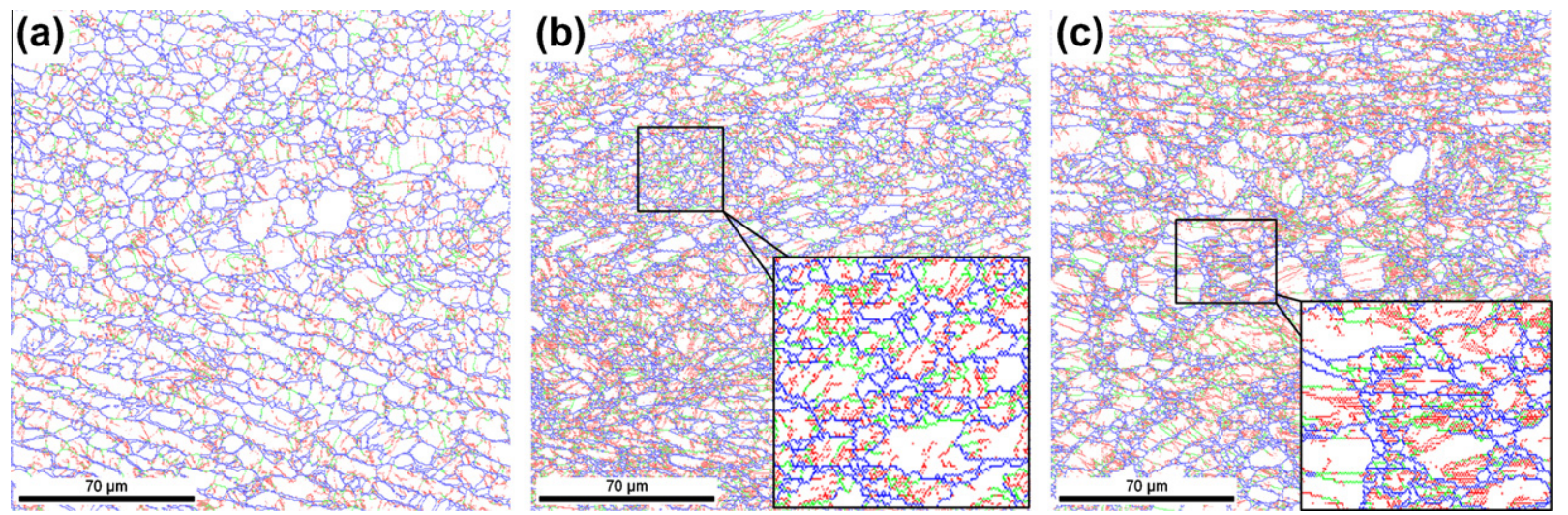

Fig. 7. GSB maps of TA15 titanium alloy obtained at $750{ }^{\circ} \mathrm{C}$ and at a strain rate of $0.01 \mathrm{~s}^{-1}$ to a strain of: (a) 0.04 , (b) 0.10 , and (c) 0.20 ; red lines correspond to low angle boundaries $\left(<5^{\circ}\right)$, green lines to grain boundaries between $5^{\circ}$ and $15^{\circ}$, blue lines to high angle boundaries $\left(>15^{\circ}\right)$. 

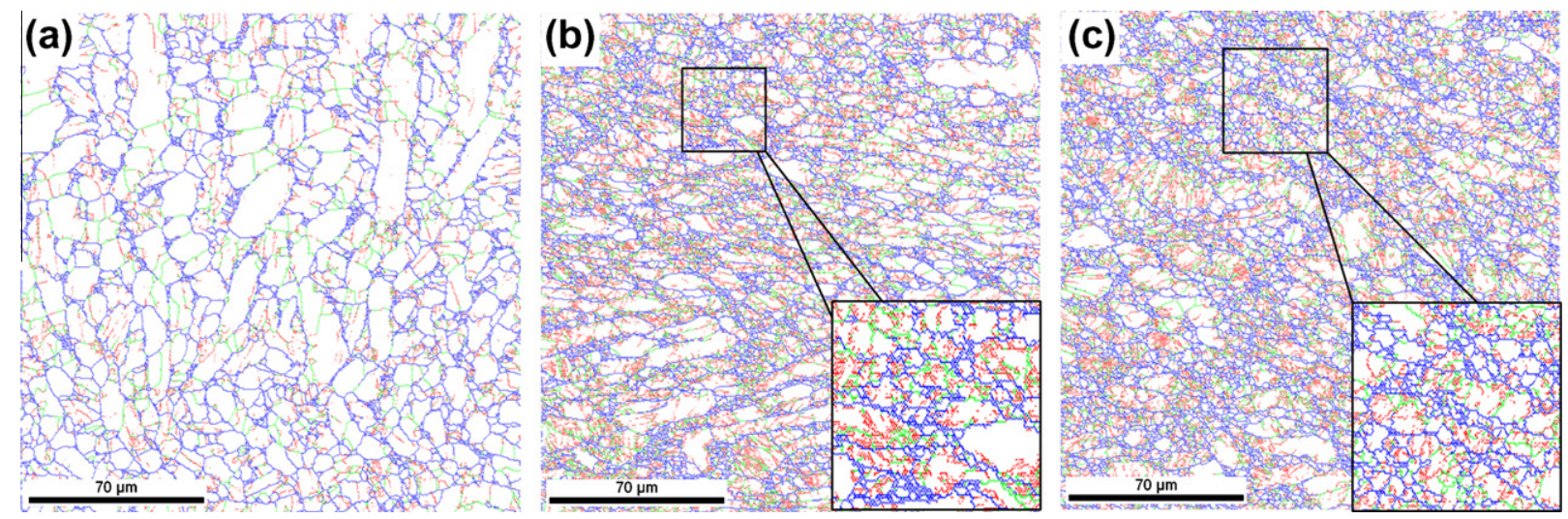

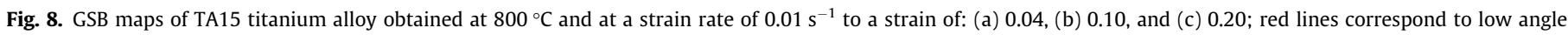
boundaries $\left(<5^{\circ}\right)$, green lines to grain boundaries between $5^{\circ}$ and $15^{\circ}$, blue lines to high angle boundaries $\left(>15^{\circ}\right)$.
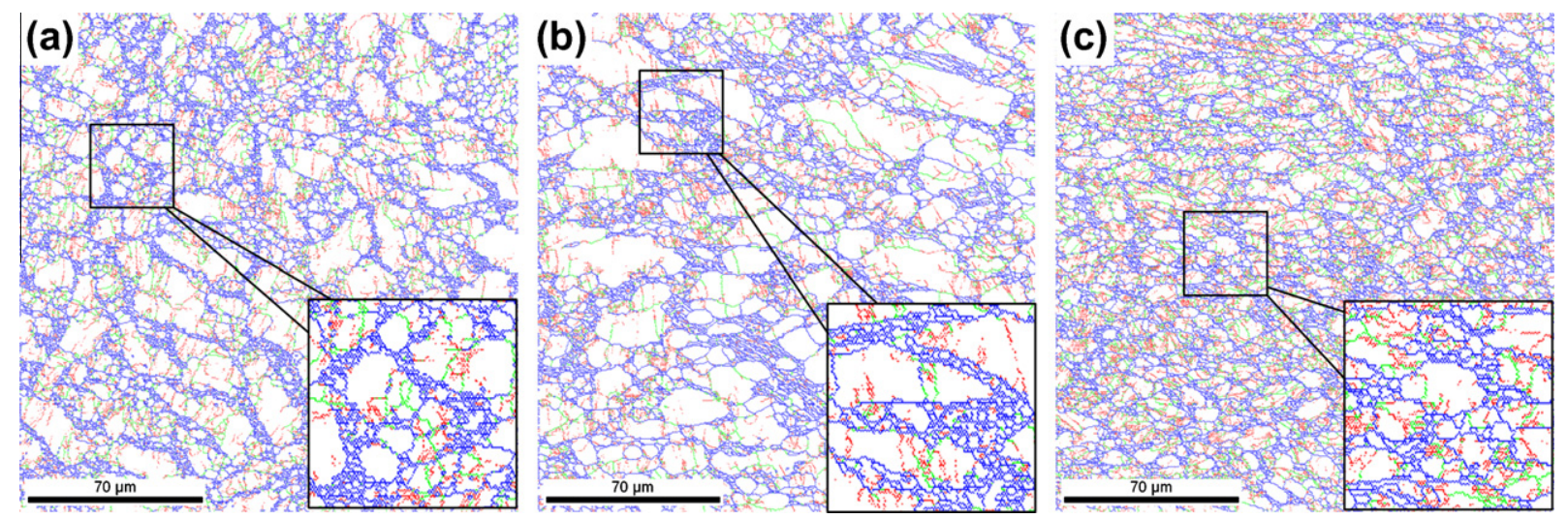

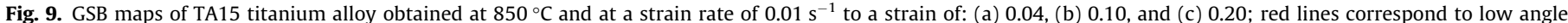
boundaries $\left(<5^{\circ}\right)$, green lines to grain boundaries between $5^{\circ}$ and $15^{\circ}$, blue lines to high angle boundaries $\left(>15^{\circ}\right)$.

At a temperature of $850{ }^{\circ} \mathrm{C}$, even at a low tensile deformation strain (e.g. $\varepsilon=0.04$ ), a lot of new equiaxed grains formed by HABs structures appeared along original grain boundaries, as shown the magnification map in Fig. 9a. Furthermore, almost all of these new equiaxed grains do not contain SBs. These new grains are identified as recrystallized grains. At this temperature, the classic "necklace structure" is observed at all tested strains. The decrease of initial grain size and the globalization are more and more obvious as the tensile strain increased from 0.04 to 0.2 .

\subsection{Crystal orientation distribution and evolution}

The crystal orientation distributions of small $\alpha$ grains (less than $2 \mu \mathrm{m}$ in diameter) and original coarse $\alpha$ grains (larger than $6 \mu \mathrm{m}$ in diameter) for TA15 titanium alloy tensile deformed under different conditions are presented in $\{0001\}$ and $\{11-20\}$ pole figures, as shown in Figs. 9-11 respectively.

At $750{ }^{\circ} \mathrm{C}$, a strong corresponding relationship between the crystal orientation of coarse $\alpha$ grains and small $\alpha$ grains exists,
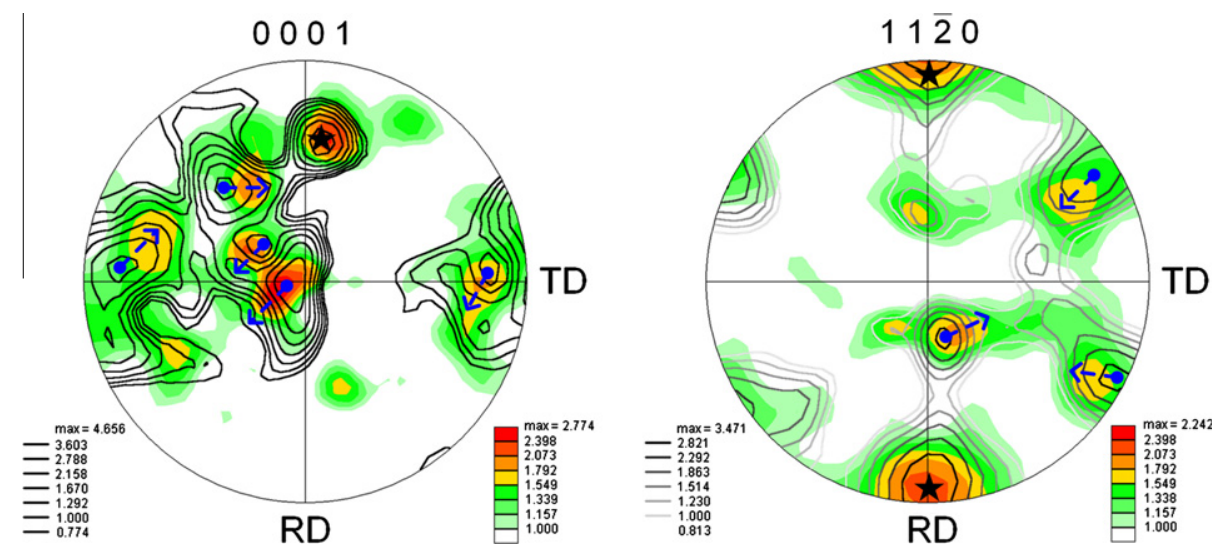

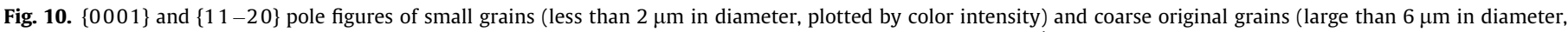
plotted by contour line) for TA15 titanium alloy deformed at a temperature of $750{ }^{\circ} \mathrm{C}$ and a strain rate of $0.01 \mathrm{~s}^{-1}$ to a tensile strain of 0.20 . 

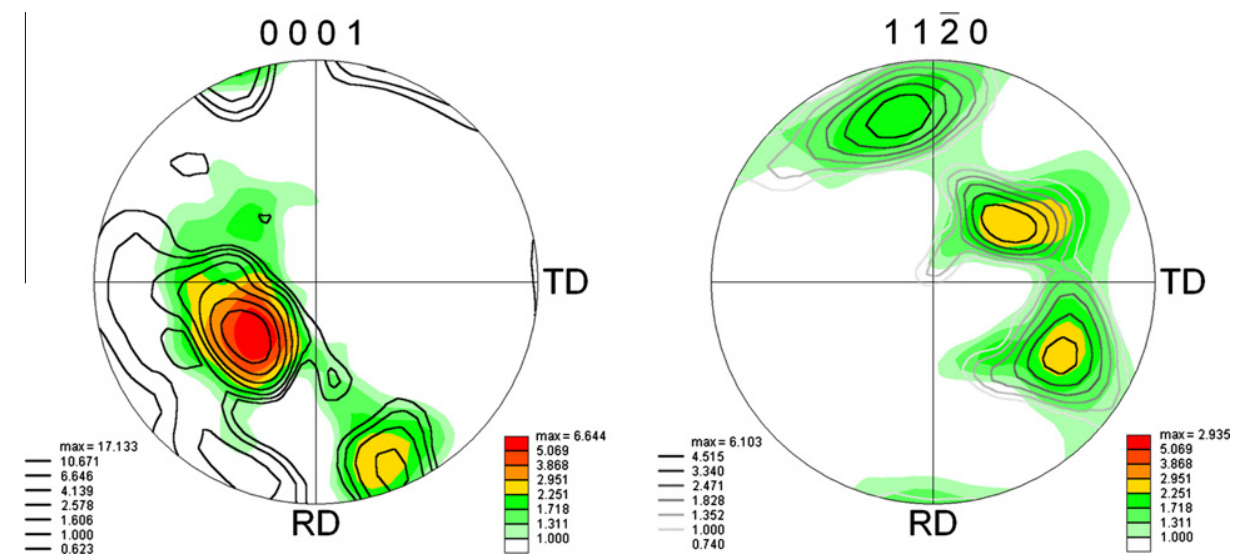

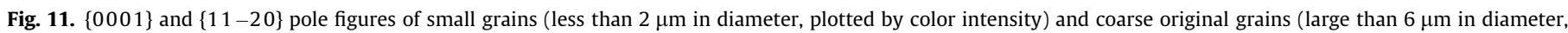
plotted by contour line) for TA15 titanium alloy deformed at a temperature of $800{ }^{\circ} \mathrm{C}$ and a strain rate of $0.01 \mathrm{~s}^{-1}$ to a tensile strain of 0.20 .
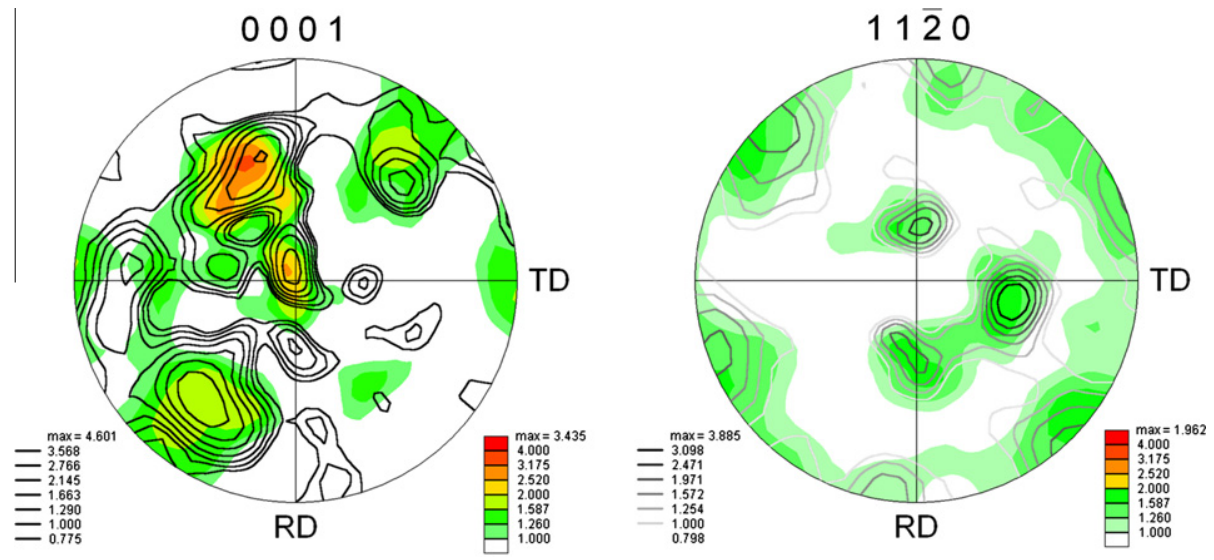

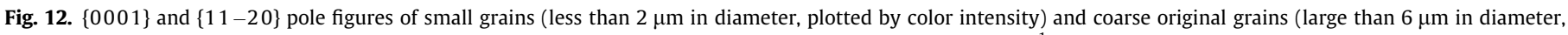
plotted by contour line) for TA15 titanium alloy deformed at a temperature of $850{ }^{\circ} \mathrm{C}$ and a strain rate of $0.01 \mathrm{~s}^{-1}$ to a tensile strain of 0.20 .

i.e. some of them correspond well (indicated by black stars) and others keep a minor shift relationship (marked by dotted blue arrows). Furthermore, the crystal orientation distribution of small $\alpha$ grains shows a weak texture.

However, at the temperature of $800^{\circ} \mathrm{C}$, a much stronger dependent relationships between the crystal orientation of coarse $\alpha$ grains and small $\alpha$ grains is presented comparing with the situation at $750{ }^{\circ} \mathrm{C}$, as shown in $\{0001\}$ and $\{11-20\}$ pole figures in Fig. 10(a and b), respectively. The corresponding EBSD data are checked and the results show that almost all grains in the scanned region have a similar crystal orientation (close to $(-1-12-3)\langle 8-5-5-3\rangle$ direction) and high Schmid factors (larger than 0.35 ) for basal slip system.

When the deformation temperature increased to $850{ }^{\circ} \mathrm{C}$ (as shown in Fig. 12), although there still exists a certain degree of dependent relationship between the crystal orientation of coarse $\alpha$ grains and small $\alpha$ grains, a relatively random crystal orientations are also presented, i.e. the texture of small $\alpha$ grains ( $\operatorname{Max}=1.96$ in $\{11-20\}$ pole figure) is much weaker than other situations.

\section{Discussion}

\subsection{Hot deformation mechanisms}

From the results of flow stress behavior, calculated activation energy and the evolution of grain/subgrain structures, it is obvious to find that, even in the narrow temperature range and at relatively low strain rate $\left(0.001-0.1 \mathrm{~s}^{-1}\right)$, the deformation mechanisms of TA15 titanium alloy are various under different hot deformation conditions.

At low temperature $\left(750{ }^{\circ} \mathrm{C}\right)$ and low strain rate $\left(0.001-0.1 \mathrm{~s}^{-1}\right)$, the calculated activation energy is $697 \mathrm{~kJ} \mathrm{~mol}^{-1}$. Obviously, this value is much larger than the activation energy for self-diffusion of $\alpha$ $\mathrm{Ti}\left(204 \mathrm{~kJ} \mathrm{~mol}^{-1}\right)$ [31] and $\beta$-Ti $\left(153 \mathrm{~kJ} \mathrm{~mol}^{-1}\right)$ [32]. Furthermore, the stress exponent value (7.28) is also far larger than those during deformation controlled by diffusion and dislocation [33].

Similar results on such high activation energy or stress exponent for titanium alloys have also been reported by other researchers. The work of Li et al. showed that the activation energy was $661.90 \mathrm{~kJ} \mathrm{~mol}^{-1}$ during the hot compression of Ti-3Al-5V-5Mo titanium alloy in $\alpha+\beta$ phase region and the reasons for high activation energy were attributed to dynamical recrystallization. Similarly, the results of Semiatin et al. [34] also showed that the activation energy was $700 \mathrm{~kJ} \mathrm{~mol}^{-1}$ during the hot compression deformation of Ti-6Al-4V with a lamellar colony microstructure at $815-995{ }^{\circ} \mathrm{C}$. They pointed out that the high activation energy value $\left(700 \mathrm{~kJ} \mathrm{~mol}^{-1}\right)$ did not have a true physical significance but was rather an artifact of the fitting of data for two-phase materials [34]. The calculated activation energy values of TC11 with lamellar microstructure were $601.12 \mathrm{~kJ} \mathrm{~mol}^{-1}$ at low temperatures (890$\left.980^{\circ} \mathrm{C}\right)$ and high strain rates $\left(0.1-10 \mathrm{~s}^{-1}\right)$ and $875.54 \mathrm{~kJ} \mathrm{~mol}^{-1}$ at high temperature $\left(995^{\circ} \mathrm{C}\right)$ and high strain rates $\left(0.1-10 \mathrm{~s}^{-1}\right)$, respectively [35]. The results were considered to be caused by 
the deformation twining and phase transformation during deformation, respectively.

Actually, different researchers related such high deformation activation energy to different reasons in addition to the dynamically recrystallization, deformation twining and phase transformation mentioned above, e.g. the effect of stress on activation energy [25], and the globularization of lamellar microstructure [35].

Because the $\alpha$ phase is "harder" than $\beta$, the deformation mainly concentrated on $\beta$ phase at the initial stage of deformation. The heterogeneous deformation on $\alpha$ and $\beta$ phase can lead to stress accumulation at the $\alpha / \beta$ interface [25]. In our current studied material, although $\alpha$ phase take around $90 \%$ volume fraction, the heterogeneous deformation on $\alpha$ and $\beta$ phase and the main deformation strain is gradually moving to $\alpha$ phase with increasing deformation strain are also obvious. This process can be indirectly validated by the evolution of grain boundaries with increasing strain, as shown in Fig. 7: the subgrain boundaries mainly distributed at thin $\beta$ layer or $\alpha / \beta$ interface at low strain (e.g. 0.04 and 0.10 ) but they gradually extend into the coarse $\alpha$ lamellae with increasing strain.

In addition, the starting microstructure is also an important factor leading to high calculated activation energy. The results of relevant studies indicate that titanium alloys with lamellar $\alpha$ starting microstructure usually have a relatively high activation energy value during hot deformation under certain conditions [25,35,36]. This result is usually attributed to globularization of the starting lamellar microstructure. The mechanisms of globularization will be discussed in the following subsection.

At medium temperature $\left(800^{\circ} \mathrm{C}\right)$ and low strain rate $(0.001-$ $0.1 \mathrm{~s}^{-1}$ ), the calculated activation energy is $357.87 \mathrm{~kJ} \mathrm{~mol}^{-1}$. Although it is far larger than the activation energy values for self-diffusion of $\alpha$-Ti $\left(204 \mathrm{~kJ} \mathrm{~mol}^{-1}\right)$ [31] and $\beta$-Ti $\left(153 \mathrm{~kJ} \mathrm{~mol}^{-1}\right)$ [32], this value lies in the range of activation energy values for dislocation creep of $\alpha$-Ti (200-360 $\mathrm{kJ} \mathrm{mol}^{-1}$ [35]) and is close to the apparent deformation activation energy of $\alpha$-Ti $\left(346 \mathrm{~kJ} \mathrm{~mol}^{-1}\right.$ [35]). Therefore, the deformation is mainly controlled by the mechanism of dislocation creep under the above mentioned conditions.

However, it is worth noting that the obtained stress exponent $(n=5.25)$ is still a little higher than other similar situations, e.g. 4.01 for TC11 compressed at strain rate $0.01 \mathrm{~s}^{-1}$ and in the temperature range $890-980^{\circ} \mathrm{C}$ [35], 3.3-3.6 for Ti-6Al-7Nb alloy in the temperature range $750-850^{\circ} \mathrm{C}$ and strain rate range $0.001-10 \mathrm{~s}^{-1}$ [37], 3.4 for Ti-6Al-4V with an equiaxed $\alpha+\beta$ microstructure in the limited strain rate range $0.0003-0.01 \mathrm{~s}^{-1}$ and temperature range $750-950{ }^{\circ} \mathrm{C}[26]$. Here, the most possible reason accounting for relatively high stress exponent is that the softening behavior (e.g. dynamic recrystallization, dynamic recover) is still weak at medium temperature $\left(800^{\circ} \mathrm{C}\right)$ and low strain rate. Although the frequency of high angle misorientation (larger than $15^{\circ}$ ) at $800{ }^{\circ} \mathrm{C}$ is higher than that at $750^{\circ} \mathrm{C}$, but it is still relatively low (less than $50 \%$ ) and significantly decreased with increasing tensile strain, as seen in Fig. 13(a and b). The relatively low fractions of high angle grain boundaries indicate that the recrystallization is still incomplete.

When the deformation temperature increases to $850{ }^{\circ} \mathrm{C}$, the calculated activation energy and stress exponent values are 163.2 $8 \mathrm{~kJ} \mathrm{~mol}^{-1}$ and 3.86, respectively. This activation energy value lies between the activation energy values for self-diffusion of $\beta-\mathrm{Ti}$ $\left(153 \mathrm{~kJ} \mathrm{~mol}^{-1}\right)$ [32] and $\alpha$-Ti $\left(204 \mathrm{~kJ} \mathrm{~mol}^{-1}\right)$ [31]. These results imply that with increasing temperature, the diffusion ability is enhanced and the deformation mechanism is the dislocation movement controlled by self-diffusion.

Furthermore, the stress exponent value $(n=3.86)$ is much lower than that at $750(n=7.28)$ and $800{ }^{\circ} \mathrm{C}(n=5.26)$. There are two possible reasons accounting for it. Firstly, the softening behavior (recrystallization) is enforced at deformation temperature $850^{\circ} \mathrm{C}$. A lot of new equiaxed $\alpha$ grains are observed along the original coarse $\alpha$ grain boundaries, as shown in Fig. 9. At the same time,
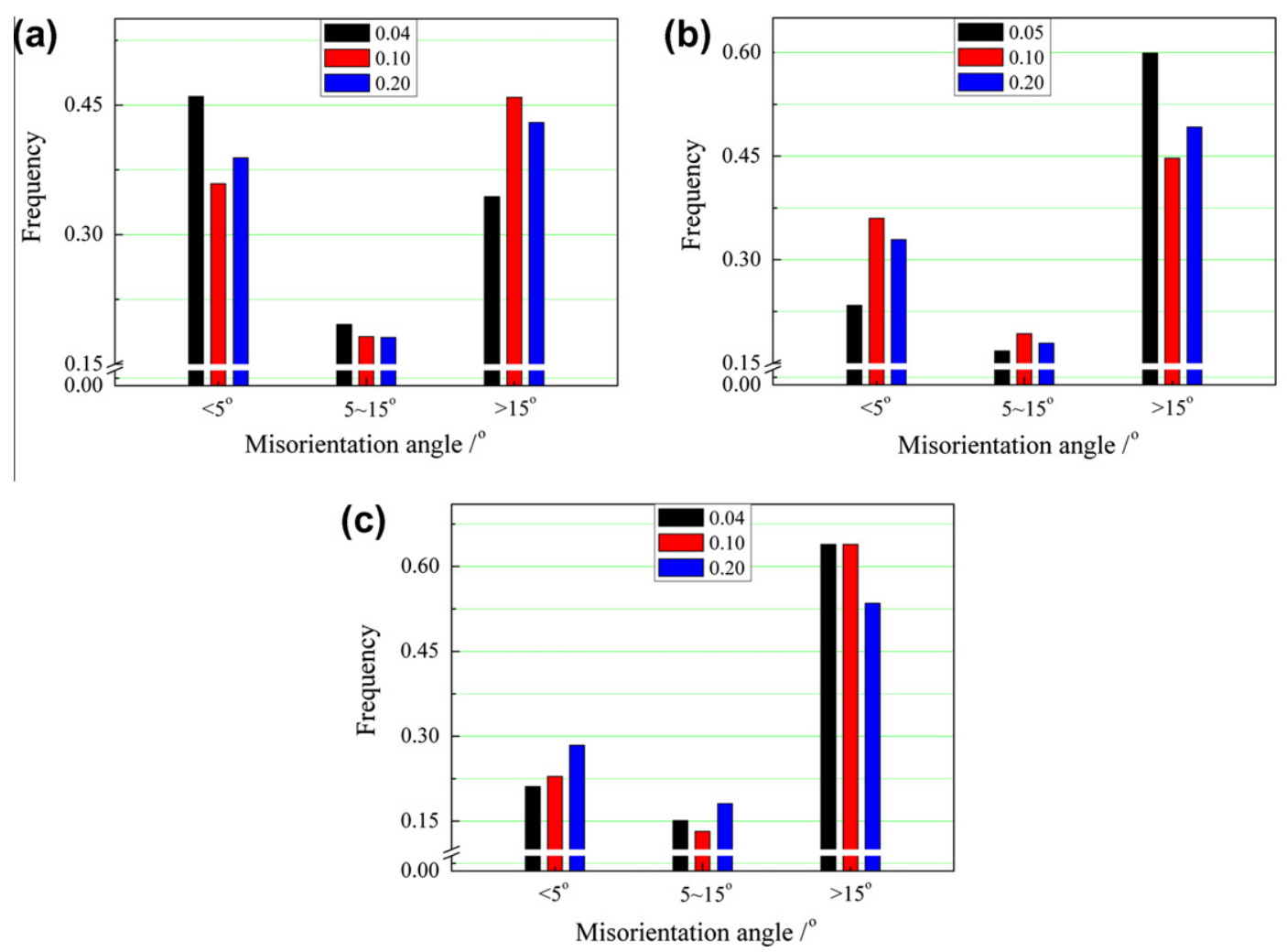

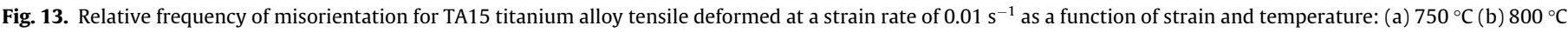
(c) $850^{\circ} \mathrm{C}$. 


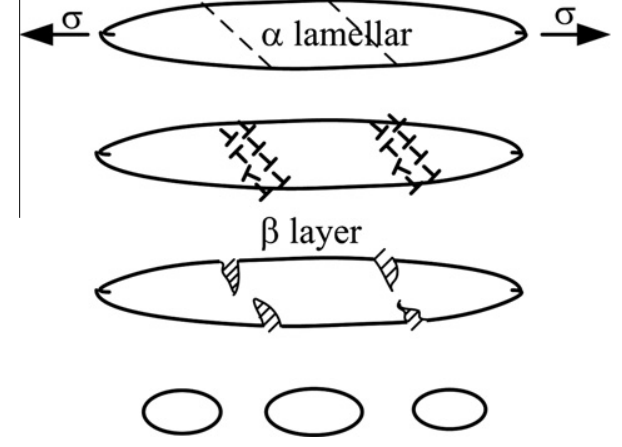

Fig. 14. Schematic illustrating the steps of globularization process [33].

the fraction of high angle grain boundaries $\left(>15^{\circ}\right)$ is around $60 \%$. It is much higher than the values at 750 and $800{ }^{\circ} \mathrm{C}$, as shown in Fig. 13c. These results show that the recrystallization is enforced and more sufficient at $850^{\circ} \mathrm{C}$. Secondly, with increasing temperature, the fraction of soft and more easily deformed $\beta$ phase [37] (comparing with $\alpha$ phase, hexagonal lattice) is increased gradually, which also lead to the decrease of flow stress and the weakening of harden behavior.

\subsection{Lamellae globularization}

Lamellae globularization is widely observed in hot deformation processes of titanium alloys and investigated by many researchers $[17,25,26,34]$. One widely accepted globularization mechanism considers that the globularization consists of two events: shearing of laths and formation of globules [17,25]. The detailed process was described by Seshacharyulu et al. [17] and the schematic illustration was presented in Fig. 14. Here, a brief description is as follows. Firstly, the plastic deformation leads to the appearance of shear and generates dislocations of both signs along the planes of shear. Simultaneously, dislocations of opposite sign are annihilated by dynamic recovery duo to the high temperature and only dislocations of same sign remain along the line of shear. Finally, the $\beta$ phase penetrates into $\alpha$ lamellae along the shear planes and the globular shape $\alpha$ grains are formed by the interfaces migration which is driven by the urge to minimize the interfacial energy.

In our current presentation, at low temperature (i.e. $750{ }^{\circ} \mathrm{C}$ or $800^{\circ} \mathrm{C}$ here), because the effect of recovery is still relatively weak, the dislocations accumulate constantly along the planes of shear with increasing strain. Obviously, the accumulation of dislocations can lead to the transition of low angle grain boundaries into high angle grain boundaries. On the other hand, the subgrain boundaries sliding and subgrains rotation to relieve the stress/strain concentration or to coordinate the deformation can also promote the formation of high angle grain boundaries. Finally, the $\alpha$ lamellae are decomposed into several short $\alpha$ grains by gradually formed high angle grain boundaries.

The processes of subgrain boundaries accumulation and the formation of high angle grain boundaries within originally coarse $\alpha$ lamellae interiors are shown in Fig. 15. Specially, the close crystal orientation distribution of the selected equiaxed $\alpha$ grains (marked by dotted black lines) which are adjacent to each other further validate that these short $\alpha$ grains are formed by accumulation of dislocations along the planes of shear or subgrains rotation, as can be seen from the crystal orientation distribution presented in inverse pole figure in Fig. 15.

However, at higher temperature (i.e. $850^{\circ} \mathrm{C}$ ), the globularization shows some different characteristics. The density of subgrain boundaries $\left(<15^{\circ}\right)$ is much lower than situations at 750 and $800{ }^{\circ} \mathrm{C}$, as shown in Figs. 9 and $13 \mathrm{c}$. The static results are also presented in Fig. 13. According to the previous discussion, this is mainly because the softening effect is pronounced at higher deformation temperature (i.e. $850{ }^{\circ} \mathrm{C}$ here). Therefore, the original $\alpha$ lamellae cannot be easily decomposed by forming high angle grain boundaries though the dislocation accumulation, which is the globularization mechanism at 750 and $800{ }^{\circ} \mathrm{C}$.

Obviously, a lot of new equiaxed $\alpha$ grains distributed along the original grain boundaries indicate that recrystallization is the dominant globularization mechanism at $850^{\circ} \mathrm{C}$. Furthermore, the $\alpha \rightarrow \beta$ phase transformation and recrystallization nucleation and growth will also gradually consume or shorten the original $\alpha$ lamellae, which also promotes the microstructure globularization. It should be noted that the coarsening and ripening effect of original $\alpha$ grains cannot be neglected at higher temperature (i.e. $850^{\circ} \mathrm{C}$ at here). (a)
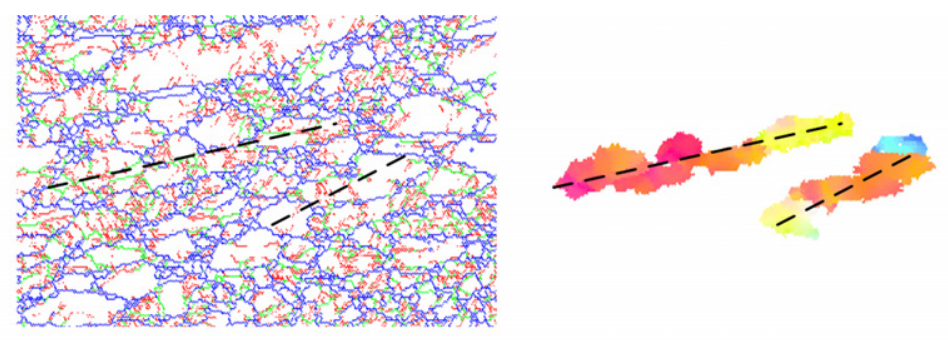

(b)

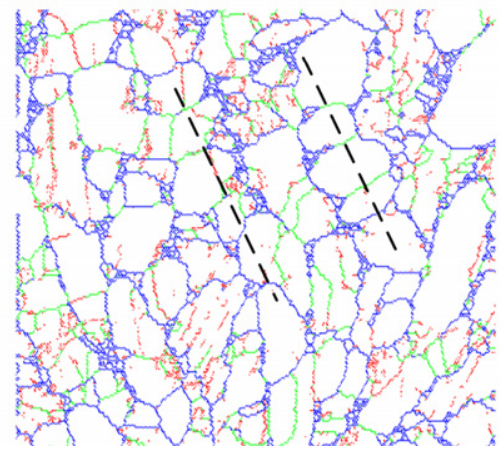

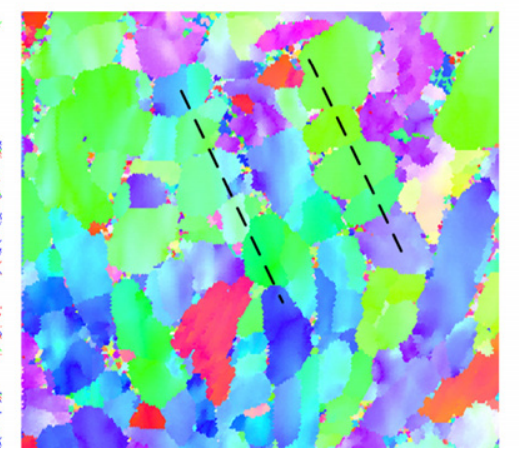
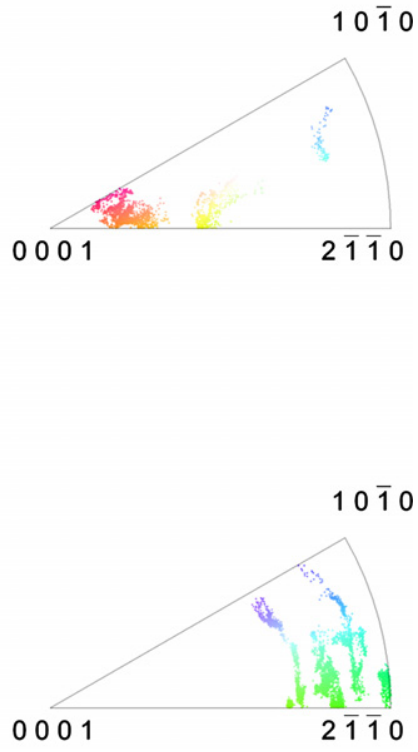

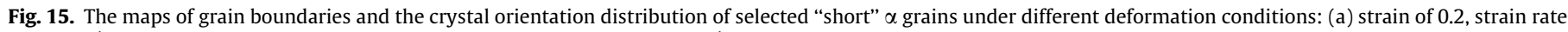
of $0.01 \mathrm{~s}^{-1}$ and temperature of $750^{\circ} \mathrm{C}$, (b) strain of 0.04 , strain rate of $0.01 \mathrm{~s}^{-1}$ and temperature of $800{ }^{\circ} \mathrm{C}$. 
This is why some abnormally thick $\alpha$ grains have been detected at $850^{\circ} \mathrm{C}$, as shown in Fig. $9 \mathrm{~b}$.

\subsection{Recrystallization mechanisms}

At the temperature of $750{ }^{\circ} \mathrm{C}$, the deformation behavior shows a significant peak and then gradually decreases to a steady state, as shown in Fig. 3a. Generally, this typical hot deformation behavior is considered to be caused by a superposition of hardening by dislocation storage and softening by (DRX) [29]. Furthermore, a lot of small equiaxed $\alpha$ grains (less than $2 \mu \mathrm{m}$ in diameter) appeared along the original $\alpha$ lamellae, as shown in Figs. 5a and 6a. These newly formed small $\alpha$ grains are usually considered as recrystallized microstructure. Based on both the deformation behavior and microstructure characteristics, we can deduce that the recrystallization occurs in $\alpha$ phase under low strain rate $\left(0.001-0.1 \mathrm{~s}^{-1}\right)$ and low temperature $\left(750^{\circ} \mathrm{C}\right)$ conditions.

However, there are three points worth paying attention to here. Firstly, a lot of low and medium angle grain boundaries $\left(<15^{\circ}\right)$ appeared in the recrystallized grain interior (see the magnification maps in Fig. 7). Secondly, the distribution of recrystallized grain is relatively heterogeneous: few new grains distribute around the original grains which have low Schmid factor for basal slip (e.g. 0-0.15 for grains marked with "1" in Fig. 6a) and several new grains appeared nearby the original lamellae with high Schmid factor for basal slip (e.g. 0.35-0.5 for grains marked with "2" in Fig. 6a). Thirdly, a strongly dependent relationship between the crystal orientation distribution of original grains (larger than $6 \mu \mathrm{m}$ in diameter) and recrystallized grains (less than $2 \mu \mathrm{m}$ in diameter) exists, as seen from the $\{0001\}$ and $\{11-20\}$ pole figures in Fig. 10. Obviously, all these microstructure and crystal orientation characteristics are different from that formed during a conventional discontinuous dynamic recrystallization (DDRX) which usually takes place in cubic metals with low or medium stacking fault energy [30] but are similar to the characteristics of a classic continuous dynamic recrystallization (CDRX) [22]. CDRX is accompanied by a continuous increase in the misorientation of low angle grain boundaries with a very limited migration of high angle boundaries. Furthermore, because these processes involve short-range interactions between dislocations and subgrain boundaries, or between adjacent boundaries, the recrystallized new grains usually present a sharp deformation textures and some extent similarity in texture components with the retained phase [22].

This CDRX has been frequently observed in hcp metals, e.g. magnesium alloys [38]. Because the new grain boundaries are formed by merging of lower angle boundaries or through accumulation of dislocations into the subgrain boundaries [22], some subgrain boundaries which are not completely merged or annihilated

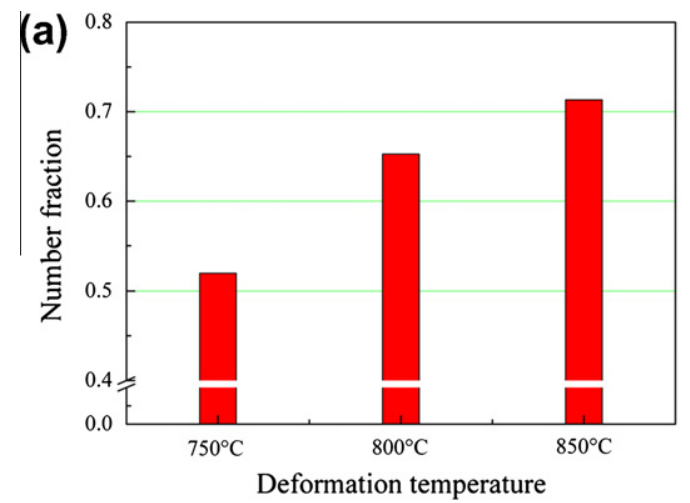

are retained in the recrystallized grains interior (see the magnification maps in Fig. 7) and the crystal orientations also show a close relationship (either completely consistent or with a small rotation, as shown in Fig. 10). Furthermore, the results of the pronounced high fraction $(47-55 \%)$ of low angle boundaries $\left(<5^{\circ}\right)$ and relatively low fraction (24-33\%) of high angle boundaries $\left(>15^{\circ}\right)$ also agree well with the basis of CDRX that mentioned above (continuous increase in the misorientation of low angle grain boundaries but limited migration of high angle boundaries).

At the temperature of $800^{\circ} \mathrm{C}$, the deformation behavior, microstructure (including grain and subgrain boundary structures) characteristics and crystal orientation distribution are basically similar to that at $750^{\circ} \mathrm{C}$. However, there are also some differences comparing with the situation at $750{ }^{\circ} \mathrm{C}$. The number and area fractions of recrystallized grains are significantly increased from $52 \%$ and $7 \%$ at $750{ }^{\circ} \mathrm{C}$ to $66 \%$ and $12.4 \%$, respectively, as shown in Fig. 16. Furthermore, the distribution of recrystallized grains is more homogeneous than that at $750{ }^{\circ} \mathrm{C}$ : the recrystallized grains distribute along almost all of the original grains and the "necklace structures" appear at some regions, as shown in Fig. 6b. On the other hand, some "completely new" grains (recrystallized grains) without subgrain boundaries are observed at strain of 0.1 and 0.2 , as shown in Fig. $8 \mathrm{~b}$ and c. These results indicate that, beside the CDRX mechanism which is the dominant mechanism at $750^{\circ} \mathrm{C}$, the DDRX mechanism also appears and plays a complementary role at $800^{\circ} \mathrm{C}$.

When the deformation temperature increases to $850^{\circ} \mathrm{C}$, the frequency of high angle grain boundaries dramatically increases to approximate $60 \%$, as shown in Fig. 13. It is much higher than that at 750 and $800{ }^{\circ} \mathrm{C}$, which is around $30 \%$ and $40 \%$, respectively. The number and area fractions of recrystallized grains steadily increased to $71 \%$ and $16.2 \%$, respectively, as shown in Fig. 16. Obviously, almost all of original $\alpha$ grains are surrounded by recrystallized grains and the necklace structure (i.e. the classic recrystallization structures) appears frequently at the strain of 0.2 , as seen in Fig. 6c. In particular, a lot of "completely newly formed equiaxed $\alpha$ grains", which contain few subgrain boundaries within their interior appeared along the original grain boundaries, as seen in Fig. 9. All these characteristics indicate that the dominant recrystallization mechanism has been changed to conventional DDRX at $850{ }^{\circ} \mathrm{C}$ from CDRX at 750 or $800^{\circ} \mathrm{C}$. The crystal orientations of recrystallized grains showing some extent random distribution (see $\{11-20\}$ pole figure in Fig. 12) and a weak correspondence to original grains (see $\{0001\}$ pole figure in Fig.12) also validate that the new small recrystallized grains are mainly formed by nucleation and growth.

In fact, the deformation condition-dependent recrystallization mechanism has also been observed and investigated by other researchers, e.g. Galiyev et al. pointed out that the mechanism can change from CDRX in the intermediate temperature range

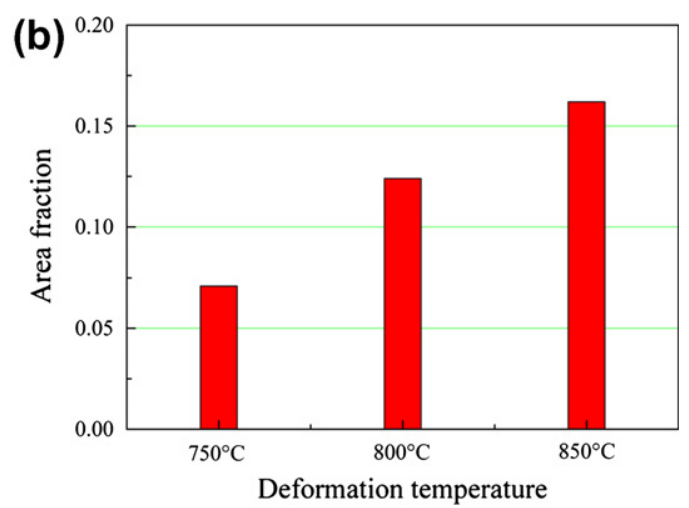

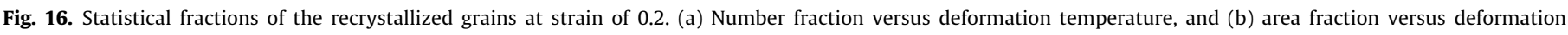
temperature. 
(473-523 K) to conventional DDRX at the temperatures ranging from 573 to $723 \mathrm{~K}$ in magnesium alloy ZK60 [29]. However, the present work is the first to discuss the evolution of recrystallization mechanism with deformation temperatures in TA15 titanium alloy. Although relatively low tensile strains may lead to an incompletion of recrystallization under all investigated deformation conditions in the present work, the underlying recrystallization mechanisms and their evolution with deformation temperatures are not affected.

\section{Conclusions}

In the current study, the deformation mechanism, lamellae globularization and recrystallization mechanisms of Ti-6Al-2Zr$1 \mathrm{Mo}-1 \mathrm{~V}$ titanium alloy in the deformation temperature range $750-850{ }^{\circ} \mathrm{C}$ and strain rate range $0.001-0.1 \mathrm{~s}^{-1}$ have been investigated by combination of activation energy calculation and microstructure evolution characterized by EBSD measurement. Based on experimental results and theoretical analysis, the conclusions can be drawn as follows:

1. The deformation behavior shows different characteristics under different conditions. The flow stress rapidly increases to a peak value, then starts to decrease continuously, and finally attains a steady state at $750{ }^{\circ} \mathrm{C} / 0.001-0.01 \mathrm{~s}^{-1}$, while no obvious stress peak appears at 800 and $850^{\circ} \mathrm{C}$.

2. Deformation mechanisms of TA15 titanium alloy are various under different hot deformation conditions: at $750^{\circ} \mathrm{C} / 0.001-$ $0.1 \mathrm{~s}^{-1}$, the thermally-activated dislocation glide is the dominant deformation mechanism; at $800^{\circ} \mathrm{C}$ and $850^{\circ} \mathrm{C}$, the deformation is mainly controlled by the mechanisms of dislocation creep and self-diffusion, respectively.

3 . In the temperature range $750-800^{\circ} \mathrm{C}$, the lamellae are decomposed into short grains by the formation of high angle grain boundaries. At $850^{\circ} \mathrm{C}$, recrystallization is the dominant globularization mechanism.

4. The recrystallization mechanism changes from $\mathrm{CDRX}$ at $750{ }^{\circ} \mathrm{C} /$ $0.001-0.1 \mathrm{~s}^{-1}$ to conventional DDRX at $850^{\circ} \mathrm{C} / 0.001-0.1 \mathrm{~s}^{-1}$ in Ti-6Al-2Zr-1Mo-1V alloy. At $800{ }^{\circ} \mathrm{C}$, both CDRX and conventional DDRX occur at low strain rates between 0.001 and $0.1 \mathrm{~s}^{-1}$.

\section{Acknowledgements}

The author (He Dong) gratefully acknowledges scholarship support from the China Scholarship Council (CSC). The author (He Dong) also wishes to thank Dr. Li (Yujiao Li) and Dr. Sarita SinghHille for their language helps.

\section{References}

[1] Wang Y, Zhu JC, Lai ZH, Cao X. Hot compressive deformation behaviour and microstructural variation of TA15 titanium alloy. Mater Sci Technol 2005;21: 1466-70.

[2] Leyens C, Peters M. Titanium and titanium alloys. Weinheim: Wiley-VCH; 2003.

[3] Donachie MJ, Titanium -A. Technical guide. 2nd ed. Metals Park, OH: ASM International; 1988.

[4] Sun ZC, Yang H, Li ZY. H-shaped component isothermal local loading forming of TA15 titanium alloy. Rare Metal Mat Eng 2009;38:1904-9.

[5] Liu Y, Zhu JC, Wang Y, Zhan JJ. Hot compressive deformation behaviors and micro-mechanisms of TA15 alloy. Rare Metals 2007;26:162-7.

[6] Weiss I, Semiatin SL. Thermomechanical processing of alpha titanium alloys an overview. Mater Sci Eng A 1999;263:243-56.

[7] McHargue CJ, Hammond JP. Deformation mechanisms in titanium at elevated temperatures. Acta Metall 1953;1:700-5.

[8] Ilyin AA, Kollerov MY, Golovin IS. Hydrogen influence on plastic deformation mechanism of $\beta$-titanium alloys of Ti-Nb system. J Alloy Compd 1997;253-254: $144-147$.
[9] Wang T, Guo H, Wang Y, Peng X, Zhao Y, Yao Z. The effect of microstructure on tensile properties, deformation mechanisms and fracture models of TG6 high temperature titanium alloy. Mater Sci Eng A 2011;528:2370-9.

[10] Chichili DR, Ramesh KT, Hemker KJ. The high-strain-rate response of alphatitanium: experiments, deformation mechanisms and modeling. Acta Mater 1998;46:1025-43.

[11] Janghorban K, Esmaeili S. Deformation-mechanism map for Ti-6 wt\% Al alloy. J Mater Sci 1991;26:3362-5.

[12] Jia W, Zeng W, Liu J, Zhou Y, Wang Q. On the influence of processing parameters on microstructural evolution of a near alpha titanium alloy. Mater Sci Eng A 2011;530:135-43.

[13] Poorganji B, Yamaguchi M, Itsumi Y, Matsumoto K, Tanaka T, Asa Y, et al. Microstructure evolution during deformation of a near- $\alpha$ titanium alloy with different initial structures in the two-phase region. Scripta Mater 2009;61:419-22.

[14] Yang Y, Wu SQ, Li GP, Li YL, Lu YF, Yang K, et al. Evolution of deformation mechanisms of Ti-22.4Nb-0.73Ta-2Zr-1.340 alloy during straining. Acta Mater 2010;58:2778-87.

[15] Nemat-Nasser S, Guo WG, Cheng JY, Mechanical properties and deformation mechanisms of a commercially pure titanium. Acta Mater 1999;47:3705-20.

[16] Sun ZC, Yang H, Han GJ, Fan XG. A numerical model based on internal-statevariable method for the microstructure evolution during hot-working process of TA15 titanium alloy. Mater Sci Eng A 2010;527:3464-71.

[17] Seshacharyulu T, Medeiros SC, Morgan JT, Malas JC, Frazier WG, Prasad YVRK. Hot deformation and microstructural damage mechanisms in extra-low interstitial (ELI) grade Ti-6Al-4V. Mater Sci Eng A 2000;279:289-99.

[18] Wang KL, Fu MW, Lu SQ, Li X. Study of the dynamic recrystallization of Ti-6.5Al-3.5Mo-1.5Zr-0.3Si alloy in $\beta$-forging process via Finite Element Method modeling and microstructure characterization. Mater Des 2011;32:1283-91.

[19] Gourdet S, Montheillet F. A model of continuous dynamic recrystallization. Acta Mater 2003;51:2685-99.

[20] Yang Y, Wang BF. Dynamic recrystallization in adiabatic shear band in $\alpha$-titanium. Mater Lett 2006;60:2198-202.

[21] Gourdet S, Montheillet F. An experimental study of the recrystallization mechanism during hot deformation of aluminium. Mater Sci Eng A 2000;283:274-88.

[22] Doherty RD, Hughes DA, Humphreys FJ, Jonas JJ, Jensen DJ, Kassner ME, et al Current issues in recrystallization: a review. Mater Sci Eng A 1997;238:219-74.

[23] H.J.M.. Development of dynamic recrystallization theory. Mater Sci Eng A 2004;387-389:203-8.

[24] Sakai T, Jonas JJ. Overview no. 35 Dynamic recrystallization: mechanical and microstructural considerations. Acta Metall 1984;32:189-209.

[25] Seshacharyulu T, Medeiros SC, Frazier WG, Prasad YVRK. Microstructural mechanisms during hot working of commercial grade Ti-6Al-4V with lamellar starting structure. Mater Sci Eng A 2002;325:112-25.

[26] Seshacharyulu T, Medeiros SC, Frazier WG, Prasad YVRK. Hot working of commercial Ti-6Al-4V with an equiaxed $\alpha-\beta$ microstructure: materials modeling considerations. Mater Sci Eng A 2000;284:184-94.

[27] Zhang XY, Li MQ Li H, Luo J, Su SB, Wang H. Deformation behavior in isothermal compression of the TC11 titanium alloy. Mater Des 2010;31:2851-7.

[28] Chen HO Cao CX, Guo L, Lin H. Hot deformation mechanism and microstructure evolution of TC11 titanium alloy in $\beta$ field. Trans Nonferr Met Soc China 2008;18:1021-7.

[29] Galiyev A, Kaibyshev R, Gottstein G. Correlation of plastic deformation and dynamic recrystallization in magnesium alloy ZK60. Acta Mater 2001;49:1199-207.

[30] Mitsche S, Sommitsch C, Huber D, Stockinger M, Poelt P. Assessment of dynamic softening mechanisms in Allvac ${ }^{\circledR} 718$ Plus $^{\mathrm{TM}}$ by EBSD analysis. Mater Sci Eng A 2011;528:3754-60.

[31] Bao RQ, Huang X, Cao CX. Deformation behavior and mechanisms of Ti-1023 alloy. Trans Nonferrous Met Soc China 2006;16:274-80.

[32] Balasubrahmanyam VV, Prasad YVRK. Deformation behaviour of beta titanium alloy Ti-10V-4.5Fe-1.5Al in hot upset forging. Mater Sci Eng A 2002;336:150-8.

[33] Frost HJ, Ashby MF. Deformation-mechanism maps: the plasticity and creep of metals and ceramics. Oxford: Pergamon Press; 1982.

[34] Semiatin SL, Seetharaman V, Ghosh AK. Plastic flow, microstructure evolution, and defect formation during primary hot working of titanium and titanium aluminide alloys with lamellar colony microstructures. Philos Trans R Soc Lond A 1999;357:1487-512.

[35] Song HW, Zhang SH, Cheng M. Subtransus deformation mechanisms of TC11 titanium alloy with lamellar structure. Trans Nonferrous Met Soc China 2010;20:2168-73.

[36] Li LX, Lou Y, Yang LB, Peng DS, Rao KP. Flow stress behavior and deformation characteristics of Ti-3Al-5V-5Mo compressed at elevated temperatures. Mater Des 2002;23:451-7.

[37] Cui WF, Jin Z, Guo AH, Zhou L. High temperature deformation behavior of $\alpha+\beta$-type biomedical titanium alloy Ti-6Al-7Nb. Mater Sci Eng A 2009;499:252-6.

[38] Humphreys FJ, Hatherly M. Recrystallization and related annealing phenomena. Oxford: Pergamon Press; 2004. 